\title{
Measurement and analysis of the water hammer in ram pump
}

\author{
W SOBIESKI ${ }^{1}$, D GRYGO $^{1, *}$ and S LIPIŃSKI ${ }^{2}$ \\ ${ }^{1}$ Department of Mechanics and Machine Design, University of Warmia and Mazury, Olsztyn, Poland \\ ${ }^{2}$ Department of Electrical Engineering, Power Engineering, Electronics and Automation, University of Warmia \\ and Mazury, Olsztyn, Poland \\ e-mail: dariusz.grygo@gmail.com
}

MS received 8 May 2015; revised 31 January 2016; accepted 23 May 2016

\begin{abstract}
This paper presents the results of experimental research of the phenomena occurring in water ram during a single cycle of its operation. Apart from a brief introduction and description of the test stand and data recording system, the work includes a broad interpretation of the obtained results. Based on the pressure waveforms recorded in two characteristic zones of the device and its detailed analysis, the single cycle of water ram is divided into three main stages: acceleration, pumping, and backflow. The waveforms of phenomena in each of these steps were considered separately. In discussion, some of the issues were supported with additional measurements, including Fourier analysis of signals from the electronic pressure transducers. The main topic of discussion based on the results recorded for the impulse valve, is supplemented by the comments that take into account the results obtained for the impulse valve (flap check valve) and for the others two (self-made) impulse valves. In the final part, in a graphic form presented is the interpretation of the phenomena occurring during one work cycle of water ram. The motivation of this work was to supplement the knowledge concerning the water hammer waveform in ram pump.
\end{abstract}

Keywords. Water ram; water hammer; water pumping; acceleration; backflow.

\section{Introduction}

The water ram is a kind of self-operated water pump whose actions are based on the use of the kinetic energy of water flowing through it. An important feature of the water ram is that a part of the water flowing through this device is lifted higher than the water level of the water supply source. The water supply source can be any watercourse, which provides adequate water flow for the system.

A water ram was invented in 1772 by John Whitehurst from Cheshire in UK. However, the device did not work automatically. Frenchman Joseph Michael Montgolfier in 1796 improved the design. Since then, the water ram could work automatically and once activated, could operate continuously. In the literature, the Montgolfier's design is usually associated with the beginning of the history of ram pumps [1]. In 1804, Eitelvein made more than 1000 experimental trials [2], but no information is available for the nature of the trials and their results. In the following years, the first publications concerning water rams were published [1, 3, 4]. In 1879, The People's Cyclopedia in New York described the invention as one of the fifty-five best inventions in the human history [5]. The water hammer phenomenon was described for the first time in 1898 by

*For correspondence
Nikolai Zhukovsky [6]. This theory helped to understand the work of the water ram better.

Water rams were widely exploited in World War II. In later times, the importance of these devices began to decrease. There are several reasons for this. The first one is inappropriate water management Law in Poland [7], the second reason was dissemination of electricity, enabling extensive use of more convenient electric pumps, and the third reason was the deterioration of the ground water quality. Another reason was the negligence of water reservoirs, rivers, canals, etc. It resulted in a loss of water flow in some earlier operating water ducts and thus the loss of part of the water supply sources for these devices. This is the probable cause why ram pumps are almost completely unknown in many countries, while in Western Europe, America and Asia, companies producing this type of devices are to be found $[5,8]$.

Because of the decrease in the importance of water rams, nowadays they are mainly treated as a technological curiosity. They have been forgotten to such an extent that they are not even marginally mentioned in textbooks on fluid mechanics and hydraulics (conclusion based mainly, but not only, on Polish academic literature). In the world literature, publications on these type of devices can be found, but these are mostly older studies limited to a general description [4, 9-13]. It is significant that much of the 
material is now available in the popular science form, without clearly indicated the names of authors or the name of the magazine, making it difficult to reference (this conclusion applies mostly to archive materials available in digital form and materials placed directly on the websites). Publications attempting to show the waveform of the phenomenon are very rare. The example is the work of Watt [4], in which the author presents his idea of the pressure waveform and velocity in a single cycle of water ram work. Calero [14] presents very similar characteristics (figure 1), except that his work is based on mathematical equations; this work also shows a graph of states for both heads of the valves (Watt described only the impulse valve). In the literature, attempts to describe the velocity changes in a single cycle work of water ram are to be found. Examples are Lansford and Dugan [1] and Tayre [15] works. In both cases, authors have used mathematical apparatus and equations of varying degrees of complexities. It should be added that in the published waveforms of velocity changes, there is generally a qualitative consistency and all displayed waveforms are similar to those shown in figure 1 (except work of Tayre [15], where at the end of the cycle, after the occurrence of backflow, there is an additional acceleration and temporary flow stop). However, there is no experimental verification and the authors emphasize that these are only theoretical and approximate waveforms. The only publication including the measurement data is the work of Lansford and Dugan [1], where authors added quite detailed commentary on the pressure changes and state of head impulse valve for two sizes of ram pump. The measurements were made using an electrical transducer and oscilloscope, as in our work, but the quality of the results is much lower there, and is quite understandable that in those

(a)

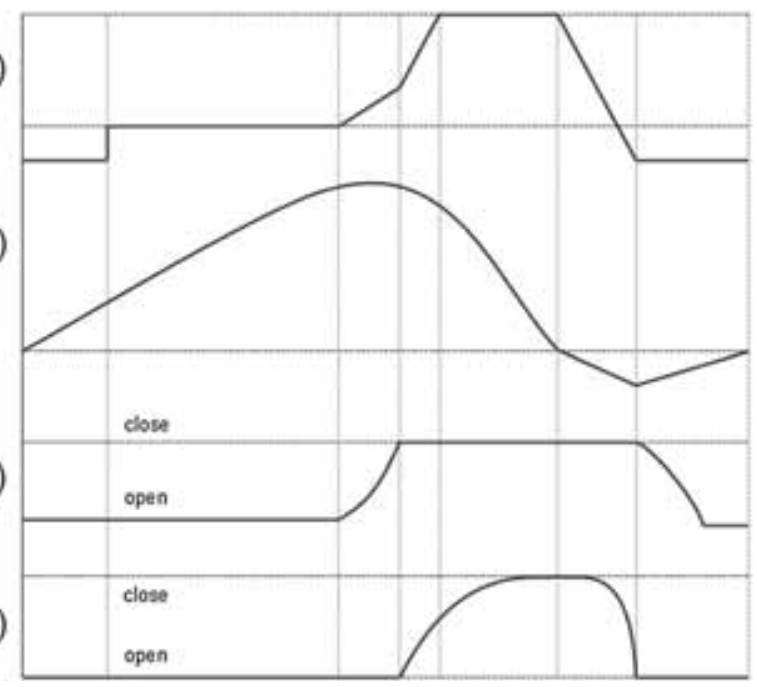

Figure 1. The graph visualizing the phenomena occurring in water ram according to Calero [14]: (a) pressure in work zone, (b) water velocity in work zone, (c) head state of impulse valve, and (d) head state of pressure valve. days measuring techniques of nowadays accuracy were not available. The authors admit that their measurements are not of satisfactory quality. Speaking of accuracy, we have in mind not only classically understood measurement error, but also its time resolution, which in our work has enabled a much better analysis of fast-changing phenomena occurring during the work of ram pump and, in consequence, the ability to understand them accurately. Important is the fact that the measurements of Lansford and Dugan [1] relate to the ram pump of classic (historical) construction, while this publication uses the modern design, based on simple hydraulic components. The literature does not provide the information about the measurements of water hammer phenomena performed on such construction of water ram.

This paper is a part of the cycle of publications. The first work [16] presented current possibilities of water ram use, indicated the group of potential customers, characterized the features of the water supply sources in the context of the use of ram pumps, showed examples of applications and gave wider motivation to start the investigations on the subject. The initial impulse for the start of our research was the observation and analysis of historical water distribution system, working without a break from 1897, located in the Kajny village near Olsztyn (northeastern Poland) and shown in figure 2. This ram pump delivers water to the water tower and then it flows gravitationally to individual buildings. A similar distribution system can also be found in Stopki village near Sepopol (located also in northeastern Poland), but it did not work for several decades; its main elements were removed and were transferred to the museum in Olsztyn.

An important factor of the study was to connect the potential use of ram pumps with current trends in a search for alternative energy sources and a general need for more efficient use of existing resources of the planet. The potential of water rams seems to be quite significant, especially that nowadays one can build it from ready-made and easily available elements, without the need for costly castings, as it was in the past.

The second work of the referred cycle [17] dealt with knowledge about stages of water ram work. The research was undertaken because there is no compliance in the literature. Various authors mention from 3 to 6 stages of a single cycle of water ram work. This paper proposes the division of a single cycle into three stages, which are acceleration, pumping, and backflow. This paper is a continuation and a significant expansion of the content of the second paper. In particular, the names and localization are changed for each stage, as well as the way of interpretation of the results.

The motivation to undertake the research was to have a complete knowledge on the ram pumps, particularly the aspects related to the waveform of the water hammer phenomenon in these devices. In the literature, there is no similar type of results, so undertaking such a research is most appropriate and desirable. 
(a)

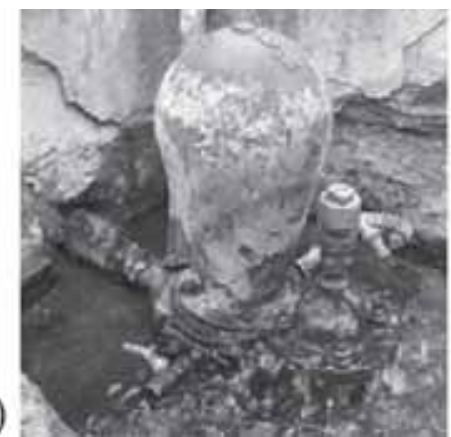

(b)

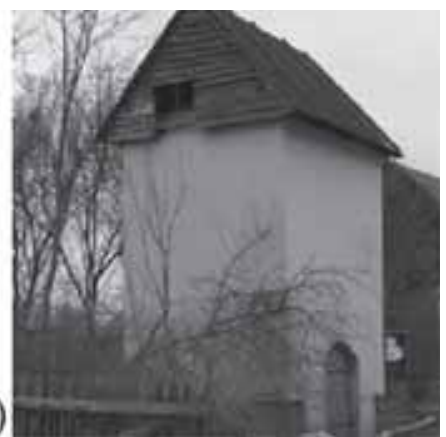

Figure 2. Ram pump in the Kajny village: (a) water ram and (b) water tower.

\section{Experiment}

\subsection{Test stand}

The scheme of test stand is shown in figure 3. It consists of a water supply system and a receiving system. The water supply system consists of a water tank (1), drive pipe (2), shut-off valve $(4,16$ and 18$)$, pressure gauge tester (15) and electronic pressure transducer (17). Components of the ram pump are a shut-off valve (19), pressure check valve (7), impulse check valve (8) and air tank (6) with air chamber (5). The receiving system consists of a delivery pipe (3) with a pressure gauge tester (12) and the second electronic pressure transducer (11). Both gauges can be shut off with valves (13 and 20). The water from the delivery pipe is poured into the upper tank (collector) (9), from where it flows through the flexible pipe (10). A valve (14) can cut off the receiving system. The electronic pressure sensors are connected to a digital oscilloscope (21) coupled with a notebook (22).

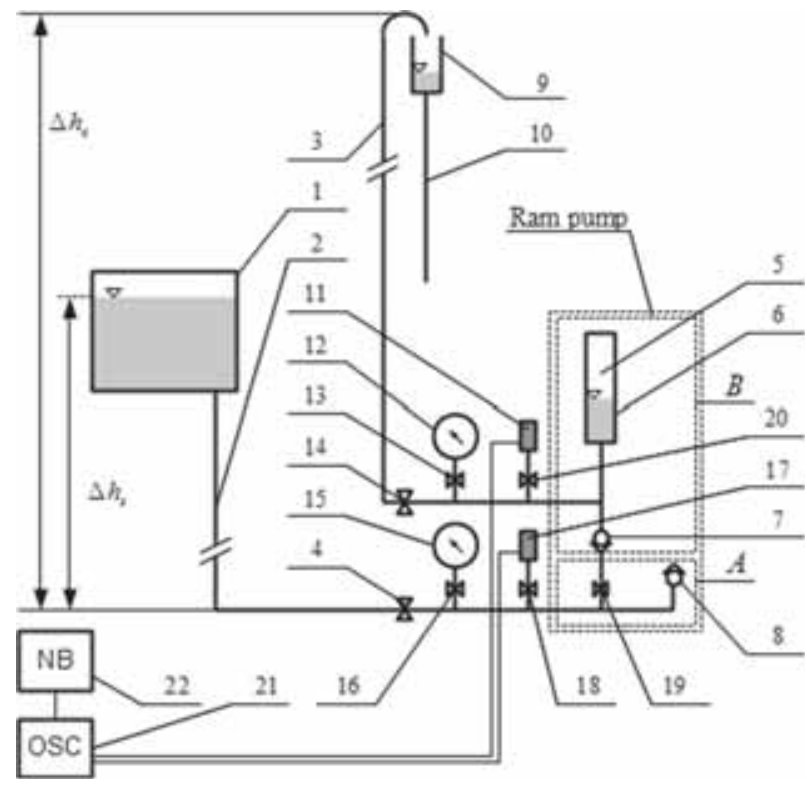

Figure 3. Scheme of the test stand.
The research position was built in such a way that it allows to regulate a height of the water supply source $\left(\Delta h_{s}\right)$ and a height of the outflow $\left(\Delta h_{c}\right)$ (figure 3 ). Change in the height of the supply source is performed through a change in the ram pump position and the outflow height through a change in the height of the collector. Supply source tank, as the most massive part of the system, always remains at the same level. Adjustment capabilities are from 3.0 to $5.5 \mathrm{~m}$ for the supply source and from 1 to $17 \mathrm{~m}$ for the height of the collector. The differences in the height are measured with the use of a measuring tape and a laser spirit level. The error in height measurement was estimated to be about $5 \mathrm{~cm}$.

Components of the research stand are described in table 1. It was assumed that design and construction of the ram pump should be as simple as possible and the measurements should be focused on the commercially available valves: the flap check valve (figure 4a) and the poppet valve (figure 4b). In addition, two others poppet valves were used [figure 4(c) and (d)]; their heads were processed to change their mass. The interpretations presented in this paper based on the measurements on water ram working with poppet check valve [figure 4(b)]. It was a typical $1 / 2$ in check valve with dismantled spring. Removal of spring allowed to install the valve in a vertical position, ensuring that the head movement is dependent only on its weight and water flow rate. Results for the other impulse valves were treated as complementary.

The volumetric flow rates of the water flowing out through the impulse valve (8) and through the flexible pipe (10) were measured using a measuring cylinder having a volume of $0.5 \mathrm{dm}^{3}$ and a timer. The accuracy of the volume measurement was $0.05 \mathrm{dm}^{3}$ and the time (taking into account the maximum human response time) about $1 \mathrm{~s}$ [18]. The average velocity in the pipes was determined based on the volumetric flow rates and pipe diameters. The internal diameter of the drive pipe (2) is $25 \mathrm{~mm}$, while the diameter of the delivery pipe is $12 \mathrm{~mm}$. The static pressure in the supply system was measured using a pressure gauge tester ranging from 0 to $0.6 \mathrm{~kg} / \mathrm{cm}^{2}$ and accuracy class equal to 0.4 . The maximum relative error for this gauge is 
Table 1. Description of the test stand.

\begin{tabular}{|c|c|}
\hline Number & Name and description \\
\hline 1 & Supply water tank, $1 \mathrm{~m}^{3}$ \\
\hline 2 & Drive pipe, $25 \mathrm{~mm}$; length, $7 \mathrm{~m}$ \\
\hline 3 & Delivery elastic pipe, $12 \mathrm{~mm}$; length, $20 \mathrm{~m}$ \\
\hline 4 & Shut off valve-steel ball valve, $1 / 2$ in \\
\hline 5 & Air chamber \\
\hline 6 & Air tank-pipe, $65 \mathrm{~mm}$; length, $0.873 \mathrm{~m}$ \\
\hline 7 & Brass check valve with flap closing element, $1 / 2$ in \\
\hline 8 & Brass check valve with flap closing element, $1 / 2$ in \\
\hline & Brass check valve with poppet closing element, $1 / 2$ in \\
\hline & Brass check valve with poppet closing element with a mass control of closure element (own design), $1 / 2$ in \\
\hline 9 & \\
\hline 10 & Outflow flexible pipe, $12 \mathrm{~mm}$; length, $20 \mathrm{~m}$ \\
\hline 11 & Electronic pressure transducer-A-10 WIKA \\
\hline 12 & Pressure gauge-range, $6 \mathrm{~kg} / \mathrm{m}^{2}, \perp 1$ \\
\hline 13 & Shut off valve-steel ball valve, $1 / 2$ in \\
\hline 14 & Shut off valve-steel ball valve, $1 / 2$ in \\
\hline 15 & Pressure gauge—range $0.6, \mathrm{~kg} / \mathrm{m}^{2}, \perp 0.4$ \\
\hline 16 & Shut off valve-steel ball valve, $1 / 2$ in \\
\hline 17 & Electronic pressure transducer-A-10 WIKA \\
\hline 18 & Shut off valve-steel ball valve, $1 / 2$ in \\
\hline 19 & Shut off valve-steel ball valve, $1 / 2$ in \\
\hline 20 & Shut off valve-steel ball valve $1 / 2$, in \\
\hline 21 & DS-1080C oscilloscope \\
\hline 22 & Notebook \\
\hline
\end{tabular}

(a)

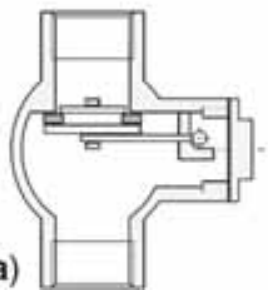

(b)

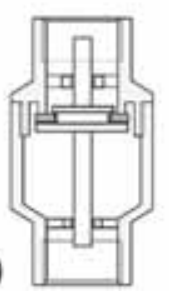

(c)

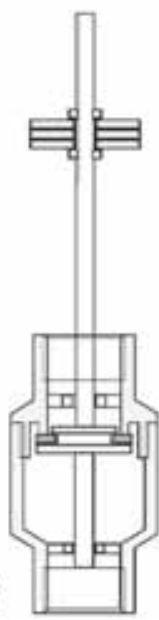

(d)

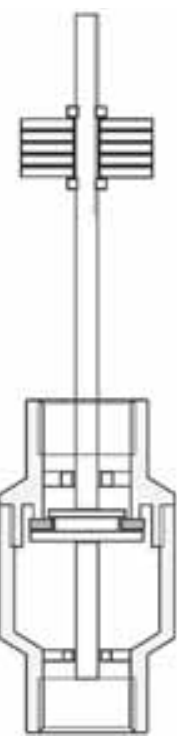

Figure 4. Schemes of impulse check valves: (a) flap check valve, $1 / 2$ in, (b) poppet check valve, $1 / 2$ in, (c) poppet check valve, $1 / 2$ in with head of variable weight, and (d) poppet check valve, $3 / 4$ in with head of variable weight.

$0.0024 \mathrm{~kg} / \mathrm{cm}^{2}(235.368 \mathrm{~Pa})$. Water temperature measurement was performed using a laboratory mercury thermometer with a measuring, ranging from 0 to $50^{\circ} \mathrm{C}$ and accuracy class 1 . The maximum absolute error was $0.1^{\circ} \mathrm{C}$.
The static pressure in the receiving system was measured using an industrial pressure gauge with measuring range from 0 to $6 \mathrm{~kg} / \mathrm{cm}^{2}$ and accuracy class 1 . The maximum relative error for the gauge is $0.06 \mathrm{~kg} / \mathrm{cm}^{2}(5884.2 \mathrm{~Pa})$. It 
should be added that not all obtained measurement data is used (for example data relating to flow rates), because it was not necessary in the context of a qualitative interpretation of phenomena occurring in ram pump.

\subsection{Water hammer registration system}

When building a registration system, it was assumed that to facilitate the interpretation of results, pressure changes must be recorded in both the zones (A and B, see figure 3). Additionally provided, was the opportunity to shut off the upper zone using a valve (19).

Electronic pressure transducers WIKA (model A-10) [19], with a measuring range from 0 to 10 bar (this range at the output of the transducer goes proportionally to the voltage in the range from 0 to $10 \mathrm{~V}$ ), and a digital oscilloscope DS-1080C EZ Digital with a measuring range of $80 \mathrm{MHz}$ and the possibility of registering $100 \mathrm{Ms} / \mathrm{s}$ for channel [20] were used for registration of the water hammer waveform. The manufacturer of the used transducers declares the maximum response time of $4 \mathrm{~ms}$. In the course of research, it is found that it is generally significantly lower. The response time caused the rejection of some of the recorded waveforms (due to the characteristic cutoff of the peak of recorded signal, so called "clipping"), but it was not a problem due to continuous work of ram pump and therefore, almost unlimited possible number of repetitions of the experiment. The oscilloscope was connected to a notebook. This test stand organization allowed controlling registration of pressure waveform from the oscilloscope, as well as through the notebook.

The most important attribute of our water hammer registration system is possibility to maintain pressure waveforms for a given period in oscilloscope's memory and then sending it to the notebook. Another worth emphasizing feature of the system is that both channels of the oscilloscope are functioning on a basis of the same time base, so they are synchronized. In this case, it allows comparing pressure waveforms from the upper and lower zones of the ram pump (i.e. zones $\mathrm{A}$ and $\mathrm{B}$ ).

Another feature of registration system based on a digital oscilloscope is the possibility of mathematical analysis of the data in real time. In this case, the most valuable is the possibility of using fast fourier transform (FFT) that allows for immediate verification of appearing hypotheses regarding the frequency characteristics of the recorded waveform and in particular, to verify whether appearing fluctuations are permanent and repeatable or random.

Oscilloscope measurements per se comes down to setting up an optimum value of time base (common for both channels) and sensitivity (for both channels independently), and then stopping waveform in an interesting point (manually or automatically, i.e. triggered with pressure peak above/below preset threshold value). When stopped, using available cursors, one can analyze the waveform to obtain its time parameters (directly) and amplitude (indirectly by converting the voltage on the pressure, what is very simple in this case, as the $1 \mathrm{~V}$ corresponds to $1 \mathrm{bar}$, and thus obtained voltage value can be read directly as the overpressure.

Considering above paragraph, the axis in all graphs presenting the oscilloscope measurements (i.e. figures 5, 6, $7,8,10,11,14,15)$ should be interpreted as follows:

- the horizontal axis is the time axis, in which one graduation corresponds to the value placed in the lower right corner of the graph (e.g. $20 \mathrm{~ms}$ in figure 5);

- the vertical axis is the axis in which the graduation depends on the channel observed (e.g. 0.1 bar for channel $2(\mathrm{CH} 2)$ in figure 5(b) and $10 \mathrm{mbar}$ for channel $1(\mathrm{CH} 1)$ in figure 5(a)).

\subsection{Determination of the type of water hammer}

Depending on the relation between the time of valve closing and the wave period, there are distinguished simple and complex water hammers. Simple water hammer occurs when the valve closing time is equal to or shorter than duration of the wave $[6,21-24]$ :

$$
T=\frac{2 \cdot L}{u},
$$

where $T$ is the period of the pressure wave (s), $L$ is the pipe length $(\mathrm{m})$, and $u$ is the propagation velocity of the pressure wave $(\mathrm{m} / \mathrm{s})$.

To determine the velocity of the hammer wave in the supply system, the Zhukovsky formula was used [6, 21-24]:

$$
u=\frac{\sqrt{\frac{(1)}{(B \cdot \rho)}}}{1+\frac{(d)}{(B \cdot E \cdot \delta)}},
$$

where $u$ is the propagation velocity of the pressure wave $(\mathrm{m} / \mathrm{s}), B$ is the compressibility of the fluid $\left(\mathrm{m}^{2} / \mathrm{N}\right), \rho$ is the density of the liquid $\left(\mathrm{kg} / \mathrm{m}^{3}\right), d$ is the diameter of the pipe $(\mathrm{m}), \delta$ is the wall thickness of the pipe (m), and $E$ is the elasticity modulus of pipe material $(\mathrm{Pa})$.

The calculations were made for the zone A, made with steel pipe. In this material velocity of pressure wave propagation is the highest. In the experiment conditions $\left(B=5 \cdot 10^{-10} \mathrm{~m}^{2} / \mathrm{N}, \quad \rho=999.006 \mathrm{~kg} / \mathrm{m}^{3}, \quad d=0.012 \mathrm{~m}\right.$, $\left.\delta=0.003 \mathrm{~m}, E=2 \cdot 10^{11} \mathrm{~Pa}\right)$, the maximum velocity of wave is about $1388 \mathrm{~m} / \mathrm{s}$. The length of the pipe in the measurement system was $7 \mathrm{~m}$, so in the experimental conditions $T \approx 0.01 \mathrm{~s}(10 \mathrm{~ms})$. During the later work, it was estimated that the opening time of the poppet check valve is about $3.6 \mathrm{~ms}$ (see comment to figure 11). Considering this, it can be concluded that the simple water hammer occurs in the analyzed system. 


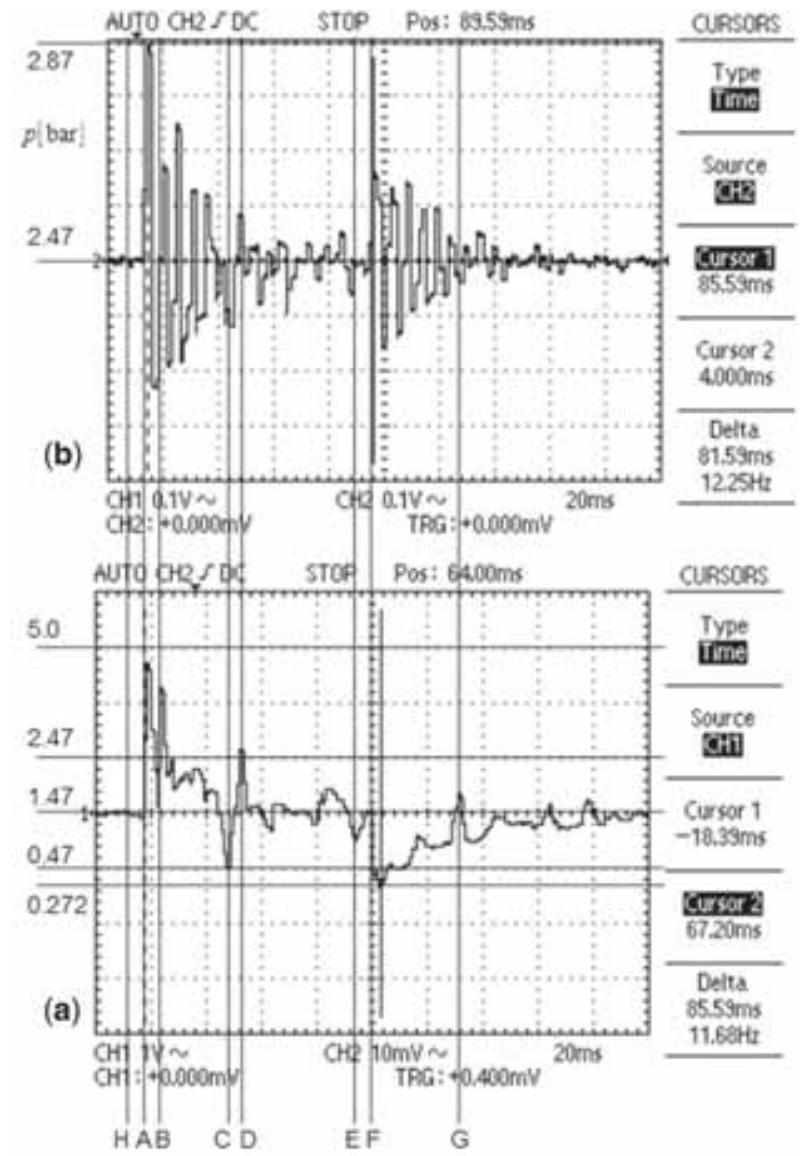

Figure 5. Example waveforms of pressure changes during the water hammer: (a) sensor in zone A, (b) sensor in zone B. Symbols are as follows: A-the end phase of the impulse valve closing (water hammer beginning), $\mathrm{B}$ - the end phase of the pressure valve opening, $\mathrm{C}$ - the point of maximum level height in the receiving system, D-the end phase of the ejection (beginning of inhibition phase), E-beginning of the pressure valve closing (backflow beginning), $\mathrm{F}$ - the end phase of the pressure valve closing and beginning of the impulse valve opening phase, and $\mathrm{H}$ - the beginning of the pressure valve closing.

An important element of the preliminary calculations, affecting the selection of the pressure transducers was estimation of the increase of pressure that can occur during water hammer. In case of simple water hammer, this increase can be calculated from the formula $[6,25]$ :

$$
\Delta p=\rho \cdot u \cdot\left(c-c_{0}\right),
$$

where $\Delta p$ is the maximum pressure increase $(\mathrm{Pa}), c$ is the average velocity flow in steady movement of fluid $(\mathrm{m} / \mathrm{s}), c_{0}$ is the final velocity (after closing or opening the valve) $(\mathrm{m} / \mathrm{s})$.

As the impulse valve closes the flow completely, the final velocity $\mathrm{c}_{0}$ is equal to zero. Therefore, while taking into account the conditions of the experiment, the maximum pressure increase in zone A (partially built from steel pipes) was estimated to be 9.33 bar. The calculation method used is very simple and does not take into account the effect of

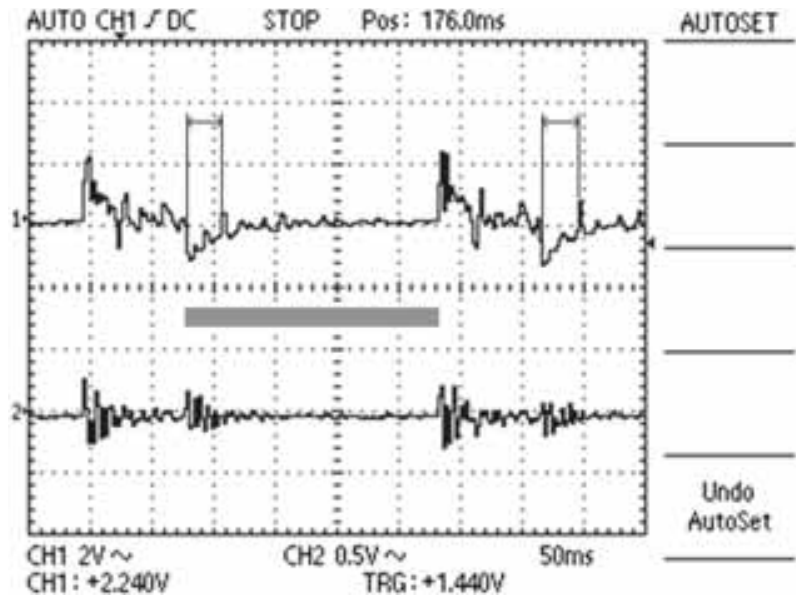

Figure 6. Exemplary simultaneous recording of pressure changes during the water hammer in sensors in (1) zone A and (2) zone B.

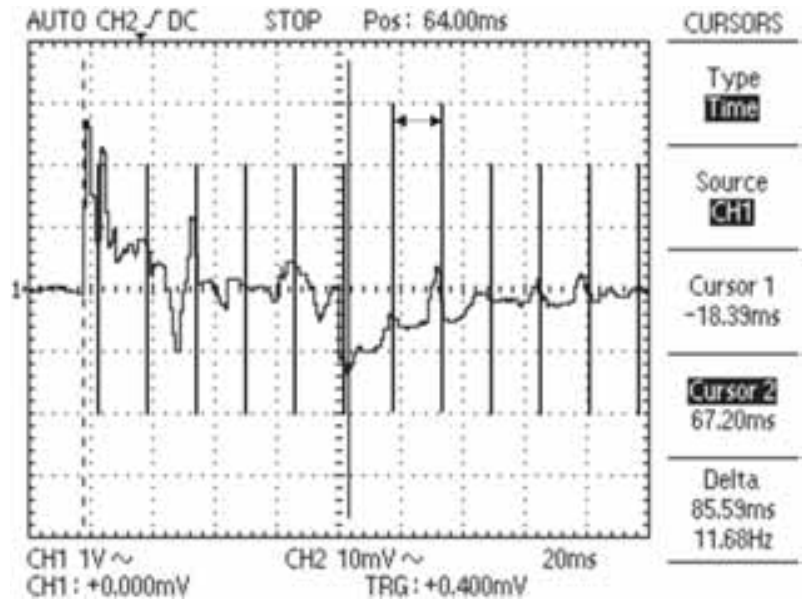

Figure 7. Marking pulsation appearing in the graph of pressure changes.

air dissolved in the water or the impact of the finite stiffness of the pipes. These factors affect the velocity of the wave by making it to slow down [21-24, 26]. Therefore, it can be expected that the real pressure increase will be smaller. Considering this, it can be concluded that the electronic transducers with a range of $0-10$ bar are suitable (as it was further confirmed in the experiment).

It is worth mentioning that the average flow rate through the zone A was approximately $0.67 \mathrm{~m} / \mathrm{s}$. The ram pump during its work consumed $0.087 \mathrm{l} / \mathrm{s}$ of water, wherein $87 \%$ was the wastewater and $13 \%$ was delivered to the collector.

Generally, while taking the measurements, we did not analyze the performance of system depending on its configuration as it will be the subject of another experiment.

\subsection{Calibration of the measurement system}

The first stage of the research was checking the correctness of the test stand, analog meters and electronic measuring 


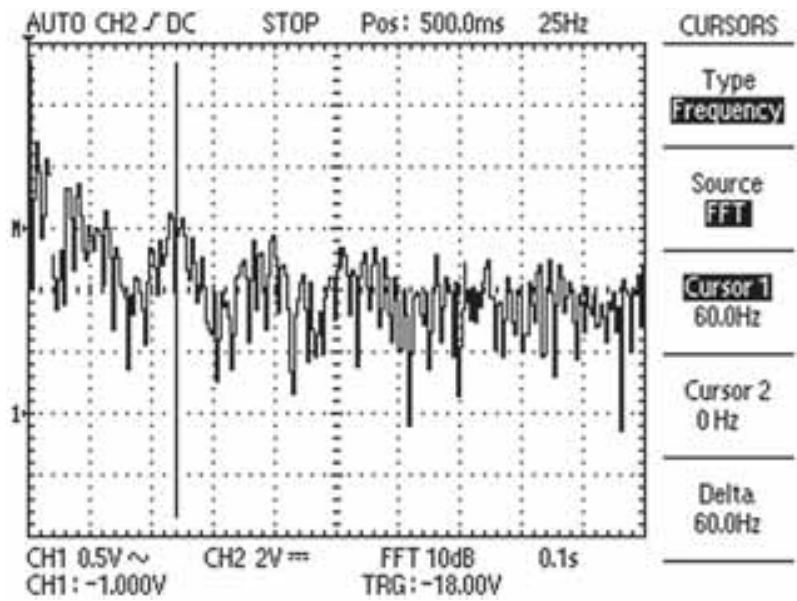

Figure 8. Frequency spectrum (FFT) of the measured signal.

system. As not to create too many variables, we decided to use a constant height source of $4.96 \mathrm{~m}$ and the constant delivery height equal to $16 \mathrm{~m}$. Another reason for the adoption of a constant measurement configuration was literature study $[3,27,28]$, in which it is mentioned that the intensity (maximum value of pressure) of water hammer should be considered in the context of the construction and working conditions of ram pump. These include water lifting height, size and performance of the ram pump, and construction details of the ram pump structure (in particular impulse and pressure valves). Measurements have proven that these parameters indeed have an impact on the amplitude and frequency of the impulses, but the character of the pressure changes was essentially the same in all cases (see section 3.4).

In theory, static pressure, prevailing at the height of the supply system, is equal to

$$
p_{s}^{t}=\rho \cdot g \cdot h_{s}^{\prime},
$$

and in gauge of the receiving system to

$$
p_{c}^{t}=\rho \cdot g \cdot h_{c}^{\prime}
$$

where $p_{s}^{t}$ is the theoretical static pressure in the supply system $(\mathrm{Pa}), p_{c}^{t}$ is the theoretical static pressure in the delivery system $(\mathrm{Pa}), h_{s}^{\prime}$ is the height of the supply source reduced by the clamping height of gauge (approximately $0.16 \mathrm{~m})(\mathrm{m}), h_{c}^{\prime}$ is the level height of collector reduced by the height the gauge mount (approximately $0.08 \mathrm{~m}$ ) (m), $\rho$ is the density of water (equal to $999.006 \mathrm{~kg} / \mathrm{m}^{3}$ for the temperature of $\left.19.6^{\circ} \mathrm{C}\right)\left(\mathrm{kg} / \mathrm{m}^{3}\right), g$ is the acceleration of gravity $\left(\mathrm{m} / \mathrm{s}^{2}\right)$.

Calculations provided the values of $p_{s}^{t}=47041.2 \pm 490 \mathrm{~Pa}$ and $p_{c}^{t}=146219.7 \mathrm{~Pa}$. Deviation of $p_{s}^{t}$ specified for the pressure is due to the inclusion of the amount of measurement error (the distance between the surface of the water in the water supply tank and the elements of the standard gauge measuring system). For collector pressure, the deviation is not given due to the unknown measurement error (collector was suspended by a system of ropes and blocks and it was impossible to accurately determine the current location of the water height in the delivery pipe), and less accurate pressure gauge mounted in the receiving system.

Static pressure measurements were also performed using electronic pressure transducers and (self-calibrated before measurements) oscilloscope. Current values of static pressures were read from the oscilloscope. They were equal to $p_{s}^{d}=47200 \mathrm{~Pa}$ for the sensor in the supply system and $p_{c}^{d}=144800 \mathrm{~Pa}$ for the sensor in the receiving system. Table 2 lists the values of the relative errors of measurements by analog and digital meters, assuming that a theoretical value is an accurate value. The results indicate that the electronic measuring system was calibrated properly, and it was reasonable to use it in further studies.

The actual pressure values indicated by the pressure resilient gauge were follows: $p_{s}^{a}=46583.25 \mathrm{~Pa}$ for the supply system (which is within the range specified in the theoretical calculation) and $p_{c}^{a}=147105 \mathrm{~Pa}$ for the collector system.

It should be added that during measurements, the level of the water in the supply tank ranged within a range of a few centimeters. It was found, however, that this is entirely irrelevant to the character of the recorded pressure waveforms.

\section{Analysis and interpretation of the results}

\subsection{Stage 1-acceleration}

The first stage of the ram pump's work considered in the literature is the period when the impulse valve is open [28-34]. In more detailed studies, such as Calero [14] and Lansford and Dugan [1], this stage is divided into two phases: the first, wherein the impulse valve head remains

\begin{tabular}{|c|c|c|c|c|c|}
\hline Localization of measurement & $p^{t}$ & $p^{a}$ & $p^{d}$ & $\delta^{a}$ & $\delta^{d}$ \\
\hline Unit of measure & $(\mathrm{Pa})$ & $(\mathrm{Pa})$ & $(\mathrm{Pa})$ & $(\%)$ & $(\%)$ \\
\hline Supply system & 47041.20 & 46583.25 & 47200.0 & 0.9831 & 0.3364 \\
\hline Collector system & 146219.70 & 147105.0 & 144800.0 & 0.6018 & 0.9805 \\
\hline
\end{tabular}

Table 2. Calculation of the pressure measurement errors.

t, theoretical; a, analog; d, digital. 
stationary and the second, in which the head starts to move, leading to closure of the valve. In this paper, the stage of acceleration is divided into three phases (see figure 5): the opening of the impulse valve (section $\mathrm{F}-\mathrm{G}$ ), open stage of the valve (section $\mathrm{G}-\mathrm{H}$ ) and closing of the impulse valve (section $\mathrm{H}-\mathrm{A})$.

Figure 5 shows a typical pressure waveform recorded with the use of two pressure transducers during a single cycle of ram pump work. It should be noted that the scale on the top sensor pressure is 10 times smaller than in the lower sensor (see the $\mathrm{CH} 10.1 \mathrm{~V}$ on the top figure and $\mathrm{CH} 1$ $1 \mathrm{~V}$ on the bottom figure-detailed description in section 2.2). The waveforms are obtained from the installation in which impulse valve was used (variant $b$ in figure 4). Further discussed waveforms are obtained for this valve also, unless explicitly stated otherwise. The pressure waveforms from the lower and upper sensors were set in a way that one can compare the states of pressure for the same moments in time. On the left side of the vertical axis, characteristic pressures are also listed.

During the acceleration stage (see figure 3), the water from the supply source (1) flows through the drive pipe (2) to the ram pump, and then through zone A and then flows out by the open impulse valve (8). During this period, the water flow rate, as well as the pressure in zone A, gradually rises. The cause of acceleration is the gravitational interaction on the water mass contained in zone $\mathrm{A}$ and in the drive pipe. Water flowing through impulse valve causes hydromechanics pressure on the head of this impulse valve according to the formula $[25,35]$ :

$$
N=\rho \cdot \dot{V} \cdot(c-v),
$$

where $N$ is the force of pressure on the valve head in the direction of water masses movement $(\mathrm{N}), \rho$ is the density of water $\left(\mathrm{kg} / \mathrm{m}^{3}\right), \dot{V}$ is the volumetric water flow rate $\left(\mathrm{kg} / \mathrm{m}^{3}\right)$, $c$ is the average velocity of water stream $(\mathrm{m} / \mathrm{s})$, and $v$ is the velocity of the head movement $(\mathrm{m} / \mathrm{s})$.

Because, in the analyzed system, both the density of the water and the geometry of the space are constant, the force of the hydrodynamic thrust on the head depends only on an average velocity of the water. As the velocity increased in time, also the force of thrust increased. Increases of the thrust force were highest in second phase of acceleration (G-H section in figure 5) when the head of the impulse valve is in rest $(v=0)$. When the water flow rate reaches a sufficiently large value, the thrust force causes the closure of the head [5, 8, 33, 36, 37]. In the literature, it is assumed that closure of the impulse valve (8) completes the first phase of the ram cycle [3, 5, 8, 28-30, 32, 33]. The authors of this study agree with this concept. It should be added that during the first stage, the pressure valve (7) remains closed all the time.

Based on figure 6 is conclusion about the time of the first phase of acceleration (the time of opening of the impulse valve) may be drawn. On all recorded cases, additional positive pressure impulse occurring about $30(\mathrm{~ms})$ after the start of the acceleration stage could be observed (end of the section indicated by the arrows in figure 6 or point $G$ in figure 5). This occurred impulse was particularly expressed in cases in which the upper zone of the water ram was cut off by the valve (19). This means that the pressure check valve (7) cannot be responsible for occurrence of this impulse. The interpretation is as follows: after the start of acceleration phase, the head of impulse valve is driven in the increasing movement. When the head is in extreme position, it is stopped, which causes the appearance of small positive hammer wave.

The exact duration of the third phase of acceleration is difficult to determine. It can be assumed that this phase begins near $\mathrm{H}$ point. From this point, a small but steady time pressure drop is noted. It should be also noted that not on all pressure waveforms, this phenomenon was clearly visible (probably due to the overlapping pressure fluctuations resulting from reflections of the hammer wave-it is mentioned later). The pressure drop on the section $\mathrm{H}-\mathrm{A}$ may be caused by the decrease of the flow resistance, resulting from the fact that the head begins to move with the stream of water. This is consistent with Eq. (6), which shows that increasing the velocity of the head causes decrease of the interaction forces between water and an obstacle placed in its way.

During the analysis of the pressure waveforms, it was noticed that the absolute pressure during acceleration varies from about $0.272(27200 \mathrm{~Pa})$ to the average value of 1.472 bar $(147200 \mathrm{~Pa})$. Large initial value of negative pressure comes from backflow occurring in the previous stage (this issue is discussed in section 3.3). The duration of the acceleration stage was $71.4 \%$ of the duration of a single cycle (about $207 \mathrm{~ms}$ ) (figure 7). Therefore, this is the longest stage, which is consistent with the information given in the literature [1, 4, 15]. For example, in a work Lansford and Dugan [1], the period of acceleration took nearly $80 \%$ of the total cycle time.

The characteristic feature of recorded waveforms is the occurrence of periodical pulsation superimposed on the main line of pressure waveform (figure 7). The literature on the water hammer shows that such pulses of constant frequency and fading amplitude are typical for the course of the water hammer phenomenon. They are caused by the reflection of wave from the boundaries of the flow system (impulse valve and the supply tank in this case). It is also known that the actual waveforms differ from theoretical as their course is not perfectly smooth, but they are usually somehow distorted (which can be seen among others work 38-40]. In this experiment, such distortions also occurred, and the main reason was loose pipes routing, so that they could vibrate and make slight swinging movements. During the measurements, it was noticed that even manual grip of pipes (by pressing it to the elements of the test position or ground) resulted in a noticeable drop in the level of interference (it should be explained that all presented 
waveforms were carried out with loosely arranged pipes). In view of the above, it can be concluded that regularly appearing pressure comes from the reflections of initial hammer wave and the distortions are the result of the lack of rigid fixation of the pipes and the interaction between the system and pressure check valve. It is worth emphasizing that all known works on the ram pumps show only the idealized waveforms as shown in figure 1 , and the aspect of overlapping reflected waves on the course of the pressure is not discussed.

Figure 7 shows that the pulse period overlapping on the main course of the pressure is about $16 \mathrm{~ms}$, which gives a frequency of $60.2 \mathrm{~Hz}$. Analysis of FFT signal from the pressure sensor (17) additionally proves that it is an important and repeating feature of the registered signal. It turns out that a characteristic frequency of $60 \mathrm{~Hz}$ can be captured (this is the peak marked with the cursor in figure 8). In the signal, there are other characteristic frequencies, but they are multiples of this particular frequency (higher harmonics). Hammer wave period obtained here $(16 \mathrm{~ms})$ is greater than the estimated in section $2.3(10 \mathrm{~ms})$. The difference in results is due to the fact that the actual stiffness of the system is less than that was assumed in the calculation approach used previously. Section 2.3 mentioned that the period of hammer wave should be slightly larger than the estimated and the applied FFT analysis confirmed this. It should be noted here that the voltage frequency of the power grid in the place where measurements were made (i.e. Poland) is equal to $50 \mathrm{~Hz}$. This fact excludes the possibility that obtained frequency (approx. $60 \mathrm{~Hz}$, i.e. the frequency of the grid in many countries, including north America) has its source in the power grid.

It should be also added that if the valve (19) disconnected the top of the ram pump, the impulse valve continues to operate cyclically. However, because there was no outflow through pressure check valve or suppression caused by the action of air chamber, the water flow more quickly obtained the momentum required to close the impulse valve and the frequency of the water hammer was greater. Based on the FFT analysis, it was found that the average frequency of the ram pump's strokes with the poppet impulse valve during normal operation cycle was $3.94 \mathrm{~Hz}$ (average from the 5 cycles) and during work with the disconnected zone B (closed valve (19)) was $5.03 \mathrm{~Hz}$. These values in individual cycles were constant and were subjected to only very slight fluctuations. Similar changes in the frequency were observed during tests of other impulse valves.

\subsection{Stage 2-pumping}

According to most of the authors, the next stage of the water ram work begins in the moment of closure of the impulse valve $[28,30]$ (although there are works in which it is believed that the next stage of the acceleration starts earlier [8, 29]). In the interpretation illustrated here, we assumed that the stage of pumping ends in the moment in which the pressure valve (19) begins to close.

In the previous section, it was explained that the increase in the time velocity of water masses flowing through the devices leads finally to the closing of the impulse valve (8). This in turn creates water hammer and a sharp rise of pressure in the system. The pressure increases enough to begin opening the pressure valve (7) and the water begins to flow through it (pressure valve) into the air tank (6) and then into the delivery pipe (3). The water hammer caused by the closure of impulse valve is clearly visible in figure 5 , at which point, this moment was marked with the letter "A". The maximum pressure recorded on the lower sensor at the time of water hammer was equal to about 5 bar, so it was approximately twice lower than the value estimated in section 2.4 , it is qualitatively consistent with expectations. It should be added that during the measurements, there were some difficulties in gripping the maximum pressure during the water hammer. In some cases, the first pressure peak could not be registered or it was clearly cut off. This effect was easy to spot and eliminate, and therefore does not affect the quality of the results, it was an effect of the limited capacity of applied pressure transducers as described in section 2.2.

To discuss the phenomena occurring in the pumping stage, diagram shown in figure 9 will be used. In acceleration stage, after passing through the impulse valve, the mass of water flows outside of the system without
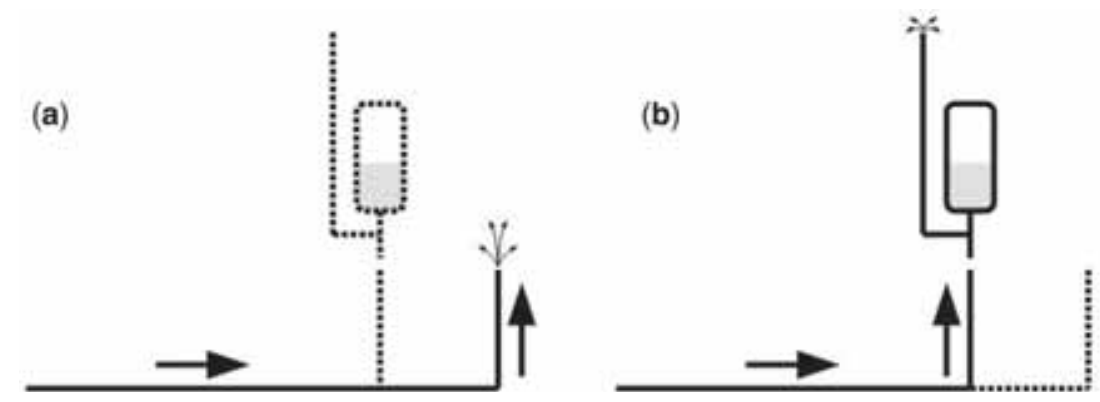

Figure 9. Direction of the flow of water mass in stage: (a) acceleration and (b) pumping. 


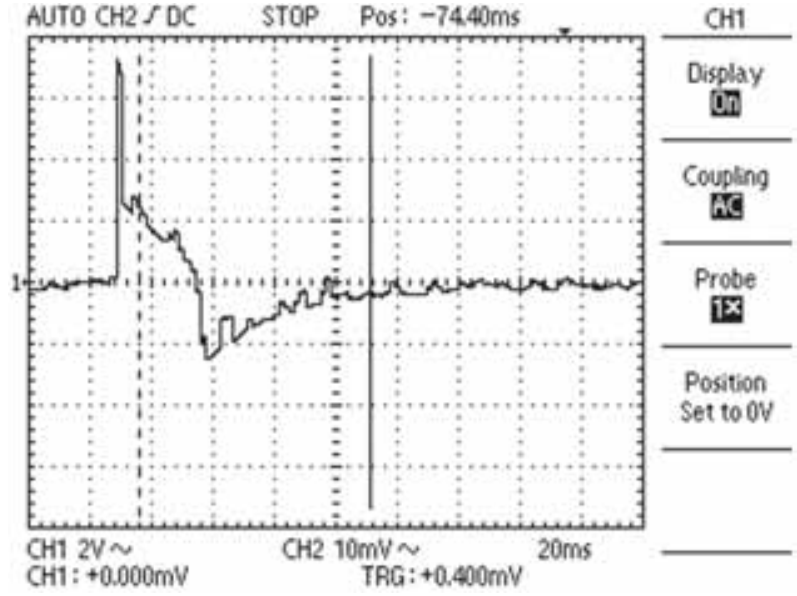

Figure 10. Example waveform of pressure changes during the water hammer on the sensor in the zone A of the water ram with closed pressure valve.

encountering any more obstacles (figure 9a). The flow resistance by this path are thus relatively small. After closing the impulse valve (8), the water can no longer flow outside and "looks for" another estuary. This estuary is the path through pressure valve (7) which begins to open as soon as the pressure hammer wave reaches to it. Rapid and simultaneous inversion of the state of the valves (7) and (8) redirects the momentum of water masses flowing to another path of system (figure 9b). However, there is no free flow and movement of water requires overcoming much greater resistance. This water mass, contained in zones $\mathrm{A}$ and $\mathrm{B}$, at this stage, the cycle does not move (actually, there are some variations of pressure resulting from previous water hammer vibration in the whole system). The emergence of resistance generates a pressure increase (see figure 5a at section A-C). It is important that along with the outflow of the water to the upper zone of the ram, the pressure in the lower zone decreases in time. The fact that pressure valve (7) opens almost immediately after the occurrence of the water hammer (closing of the impulse valve), indicates that the upper sensor also recorded water hammer, exactly at the same time as the bottom sensor (line A in figure 5). The course of water hammer in the upper zone is shown well in figure $5 \mathrm{~b}$. It is characteristic that the fluctuation of pressure in this zone (reaching upto about 0.5 bar) undergo rapid attenuation due to the air chamber existing in the system. The frequency of the pressure oscillations depends on the mass of the water in the upper zone and is not in accordance with the characteristic frequency of the reflections of the water hammer (see description to figures 7 and 8). It is worth noting that the surface of the water in the air tank varies slightly according to pressure changes. This note applies to the whole cycle of work of ram.

A characteristic feature of the recorded pressure waveform is the appearance of a secondary water hammer on the bottom sensor after the start of the pumping stage

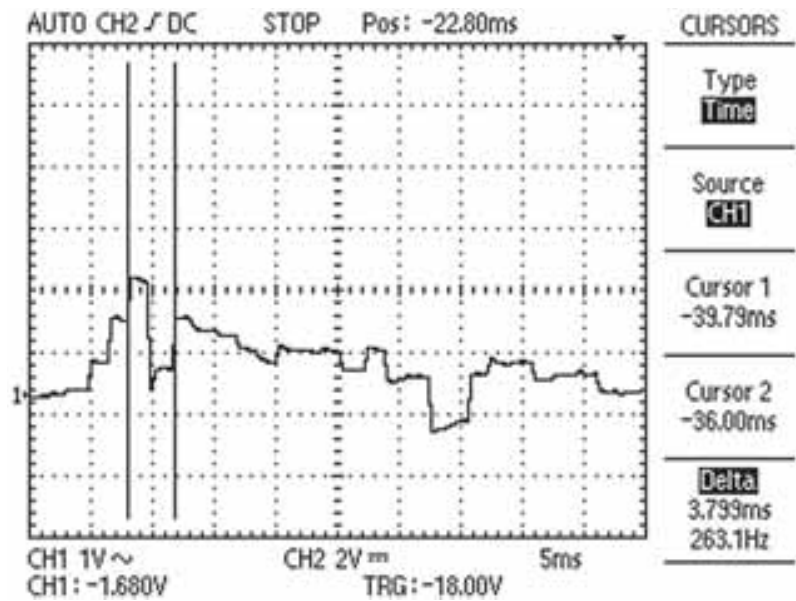

Figure 11. Measurement of the time interval between the characteristic peaks of start of compression stage.

(figure 5a, point B). Because this effect did not occur in cases where the zone B was cut off by a shut-off valve (19) (figure 10), it can be assumed that the pressure valve (7) causes it. This point is interpreted as the moment of the end of pressure valve opening: when the head of the valve is stopped, it generates additional positive pressure wave. If this interpretation is correct, the time of the fully opening of the pressure valve is approximately $3.6 \mathrm{~ms}$ (average of five measurements) (figure 11). Considering the fact that the stop of movement after the closing of the impulse valve and the formation of the pressure flow wave retreating up, also require a certain amount of time [1], the time of the pressure valve closing may actually be even shorter. This result is consistent with observations of Lansford and Dugan [1], who state that the pressure valve opens and closes "immediately". Similar comments were found in the works of Watt [4] and Jeffery et al [41]. Interestingly, this information is in conflict with graphs of velocity changes (see figure 1) in works by Calero [14], Tayre [15] and Watt [4], where relatively long periods with the valves opening or closing are clearly marked. The explanation may be the desire of authors to highlight the different stages of the course of the phenomena in a way that the individual periods are not presented in the same time scale. With regard to the time of impulse valve opening, estimated to be about $30 \mathrm{~ms}$, and time of pressure valve opening, estimated to be around $3.6 \mathrm{~ms}$, one can see that the velocity of movement of the valve heads (at least in the case of being analyzed) should differ by about 1 order of magnitude. This conclusion is consistent with the results of visual observations. Movement of the impulse valve head was clearly observable and it was important part of the cycle of the ram pump work. It was clearly observed when greater mass of the valve head was used. In the case of the impulse valve, there is no possibility of its "immediate" opening or closing. 
It should be noticeable in figure 7, that precisely on the lines, depicting moments of pressure pulsations (mentioned in the previous paragraph). It can be seen that the first line does not fit into an equal period and that it should be placed a little earlier (then, the pulses are even). This means that at the beginning of this stage appears a factor distorting the period of water hammer. This factor is the air chamber accumulating energy of the pressure wave. This effect is particularly strong after the opening of the pressure valve, where the air chamber volume changes are the largest. The literature [6] mentions that the addition of the elastic elements (in the cited work, it was a bypass made from polyethylene pipe) decreases propagation velocity of the pressure wave. However, according to Eq. (1), smaller velocity of the wave means greater period. Consequently, the interpretation that the check valve begins to open at the time as the initial water hammer and appearance of the secondary water hammer in this part of the cycle is result of the valve head stopping appears to be more justified. Change of the characteristic frequency and the distortion arising from pipe vibrations can be the clues why on the characteristic frequency graph (figure 8), the characteristic frequency of recorded signals are not distinguished clearly on the background.

Returning to the interpretation of the phenomena, it should be explained why during the pumping stage, there is a significant decrease (point $C$ ), and then increase in the pressure (point $\mathrm{D}$ ). This phenomenon results from inertia of water mass in the upper zone of the ram and in delivery pipe. Rapid and strong increase of pressure in system executed by water hammer causes the ejection of the masses in outflow direction. Because the flowing matter is continuous, the effect of this "ejection" is occurrence of a strong negative pressure. A moment later, these water masses by actions of gravity and elasticity of the system are suppressing, what in return manifests is temporary increase of pressure. This occurs only once. In this example, point $\mathrm{C}$ occurred at about $28 \mathrm{~ms}$ after the start of pumping. This is $9.65 \%$ of the duration of the whole cycle of ram. It can be assumed that in general case, the amplitude of the pressure variation depends on the amount of water in the upper zone of ram and in outflow pipe, as well as on the volume of the air chamber and stiffness of the pipes.

After the occurrence of the phenomena described above, there is still pumping, but due to the fact that the water mass has already been set in motion, the pressure in the system is smaller than before. The pressure continues to fall until the flowing water mass is completely inhibited. This is the point $\mathrm{E}$ in figure 5. This point ends the stage of pumping.

After analyzing phenomena occurring in the pumping stage, division of this stage on ejection phase (section A-D) and inhibiting (section D-E) can be proposed. This division is conventional, because of the fact that inhibiting momentum of water masses occurs during the whole period of pumping stage.

\subsection{Stage 3-backflow}

The stage of pumping ends at the moment of the water movement stop. Because the pressure valve (7) is opened and the height of water columns on both of its sides are different ( $\Delta h$ in figure 12), the system endeavors to equilibrate (typical system of connected tanks). As a result, the water starts to flow from zone B to zone A. Because in zone A, the movement in the direction of the impulse valve is not possible, the water is directed to the supply tank (1) by drive pipe (2). Dropping water mass in zone B pulls the head of pressure valve (7) which closes after a short while. The period lasts about $6 \mathrm{~ms}$ and closure of the valve (7) is assisted by gravity. During the backflow stage, the velocity increases, also increases flow resistance (to the square of the velocity, according to the Bernoulli formula). Because of these resistances in drive pipe, during this period a regular increase of pressure (section E-F) is recorded in lower sensor. Backflow lasts until the moment when the head valve (7) is in the end position and prevents further water flow. The valve closing causes smaller water hammer in zone $\mathrm{B}$ (point $\mathrm{F}$ in figure $5 \mathrm{~b}$ ).

After closing a valve (7), the mass of water flowing by drive pipe (2) at the source (1) cannot stop immediately because of the inertia of water in the system. This inertia causes negative pressure [point $\mathrm{F}$ in figure 5(a)], which sucks the water from the impulse valve and start opening it. The work cycle of the water ram starts again.

It should be noted that the check valve is closing relatively quick, while the impulse valve is opening at rate dependent on its mass: the bigger it is, the longer is the stage of acceleration. This is confirmed by the literature information and measurements made on the test stand, which show that the pulsation frequency decreased with increasing mass of the valve head.

The backflow stage is very important in the context of ram pump start-up. The ram starts if the height of the water column in the delivery pipe (3) is greater than the height of the source $(\Delta h>0)$. If the ram had previously worked and the delivery pipe is completely flooded with water, there should be an automatic start (this was in all tested configurations) in each case. If, however, the ram start-up occurs

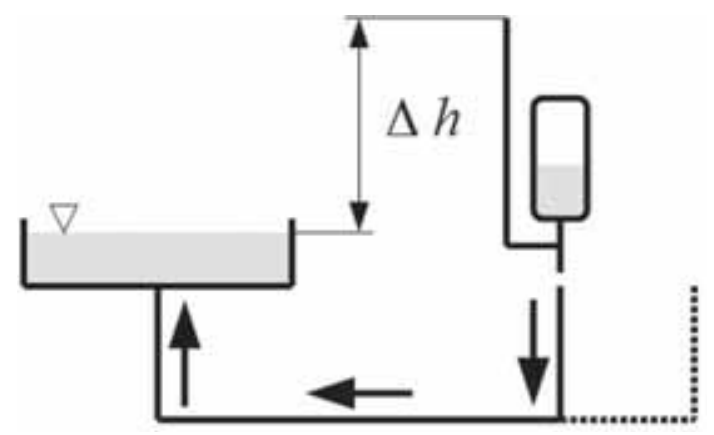

Figure 12. Imbalance of static pressure at the end of a pumping stage. 
for the first time and the delivery pipe is empty, the start-up method depends on the diameters of drive pipe (2) and delivery pipe (3). If the diameter of the delivery pipe (3) is much smaller than the diameter of drive pipe (2) (see figure 3), the first portion of water that flows to zone B after valve opening (7), fills the delivery pipe to the adequate height. The backflow stage occurs and ram starts to work automatically. Inside installations where the diameter of the delivery pipe is large, the same amount of water is to fill it to a lower height. Consequently, the conditions $(\Delta h>0)$ are not met and the stage backflow will not occur. In such situations, there is need to manually open the impulse valve (8) several times by pushing its head until such time when the height of the water column in delivery pipe will be adequately large.

\subsection{Graphic form of a single cycle of hydraulic ram}

Interpretation of the measurement results allows presenting a qualitative graph of changes in the ram pump during a single cycle (figure 13) of work. This graph is a summary of the previous three paragraphs of this paper. Due to the qualitative character, the vertical axis is not calibrated, it shows only changes in individual zones. Along the horizontal axis percentages of duration of each characteristic stages in a single cycle are marked (axes description are found in section 2.2). The time scale bases on measurements using the impulse poppet valve, for which the duration of a single cycle was $290 \mathrm{~ms}$.

Figure 13a indicates simplified (i.e. devoid of additional pulsation), but characteristic for all measurements, course of pressure change in zone A of the ram pump. The course was drawn in the same format that was being recorded during the measurements (the chart begins just before water hammer occurrence). Characteristic points are marked on the graph, same as in figure 5. As a result of the analysis of results, graph of the approximate position of the valve head was plotted [figure 13(b) and (c)].

Figure 13 shows the predicted quality waveforms of velocity changes of the water flowing through the impulse and pressure valves. These waveforms are imposed on the lines showing the states of valves. According to the adopted interpretation, at the beginning of acceleration stage, the pressure valve is closed and impulse valve is opened. The pressure valve is closed so that the water flow through the valve is zero (in whole acceleration stage). Impulse valve is opened under the backflow so that the direction of the velocity is directed towards the top flow. Unfortunately, it was impossible to determine exactly how long the backflow in the figure 13 lasts, but it was assumed that it lasts approximately as much time as for the opening of the impulse valve. After completion of the backflow, the velocity flow through impulse valve gradually increases. After closing this valve, the flow is not possible and the velocity drops to zero. At the beginning of the second stage, the pressure valve begins open to, causing rapid movement of masses from zone A to zone B. The velocity of the water masses is reduced in time due to the gradual loss of momentum of the water stream (hence inclination in the draw). At the end of this stage, the water flow rate through the valve drops to zero. In the third stage, the direction of water flow through the pressure valve changes, and the velocity gradually increases until complete blockage of flow through the head of this valve. The impulse valve in backflow stage is closed all the time.

Course of phenomena in ram pump presented here seems to be characteristic for this type of devices. Figure 14 shows the course of pressure in the pressure flap valve. It may be noted that it is almost identical (in terms of the character, amplitude and frequency) with the one recorded for the case of the poppet valve (see figure 5).

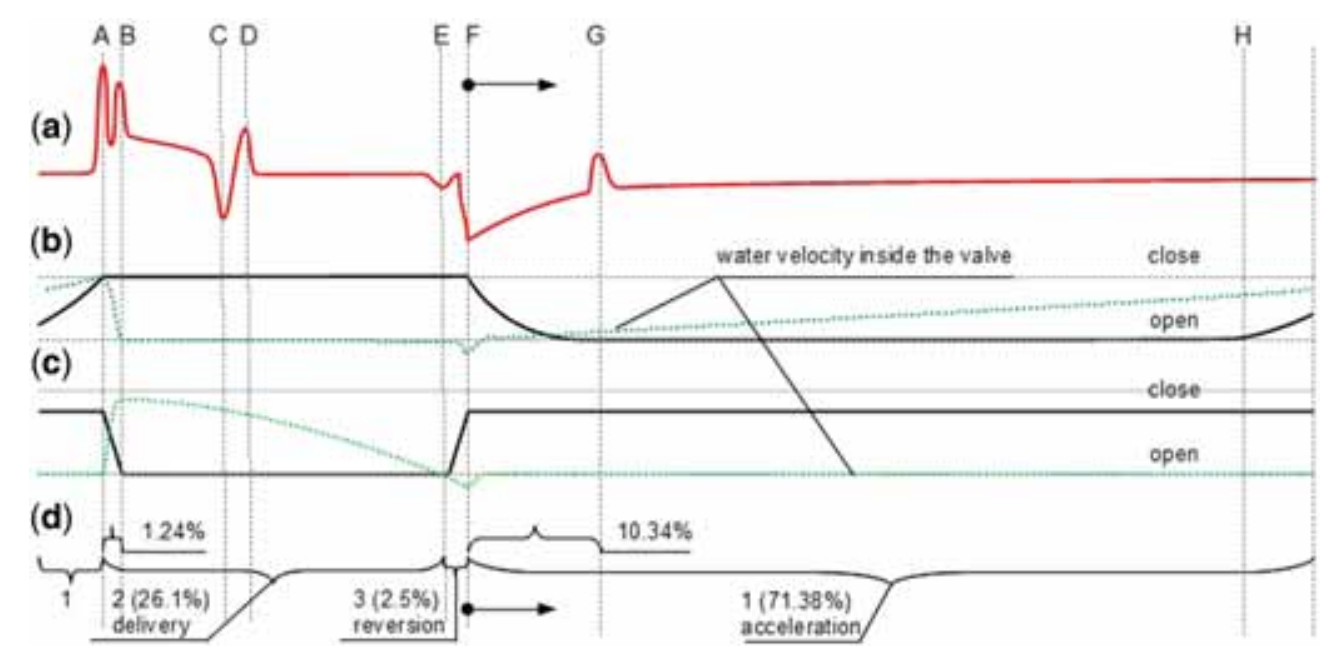

Figure 13. Graph of changes in hydraulic ram: (a) pressure in zone A, (a) position of the head of the impulse valve, (c) position of the head of the pressure valve, and (d) time percentage of the various stages in a single cycle of ram work. 


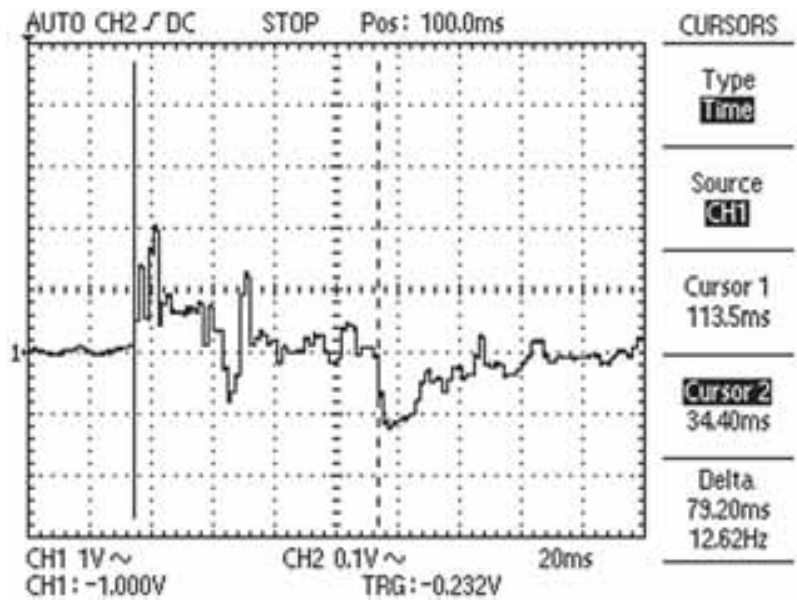

Figure 14. The waveform of the water hammer recorded at the lower sensor for impulse check valve.

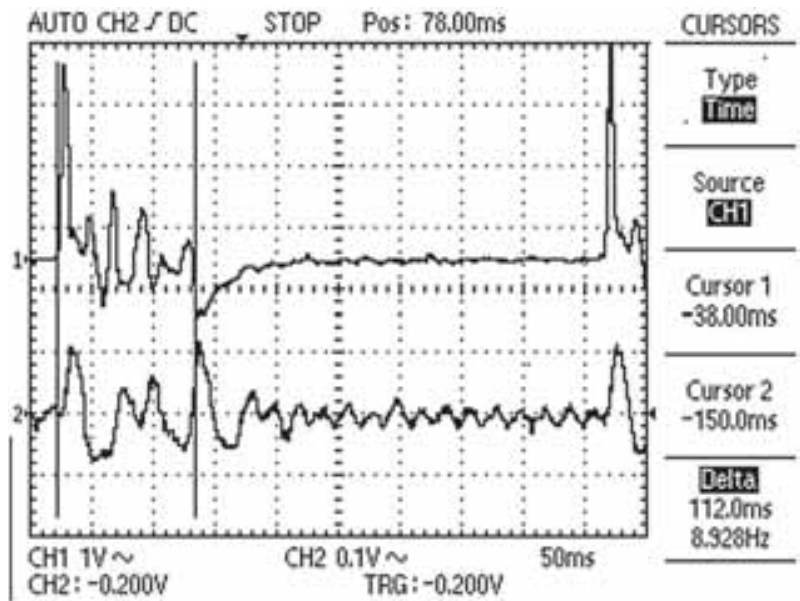

Figure 15. Waveform of water hammer registered on lower sensor (top line (1)) and upper sensor (lower line (2)) for the selfmade valve (option c in figure 4).

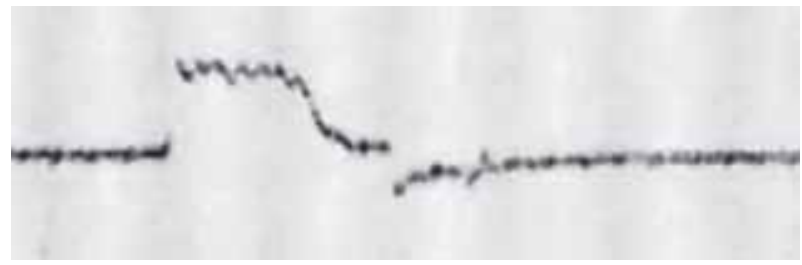

Figure 16. Example of registration of pressure changes from ref. [1] (original negative).

In the case of self-made valves, the character of pressure changes was similar, but the recorded parameters have changed (figure 15). The main difference was that with the increasing mass of the impulse valve head the frequency decreased, while the values of recorded pressures increased. A more detailed analysis of this issue is planned for the future.

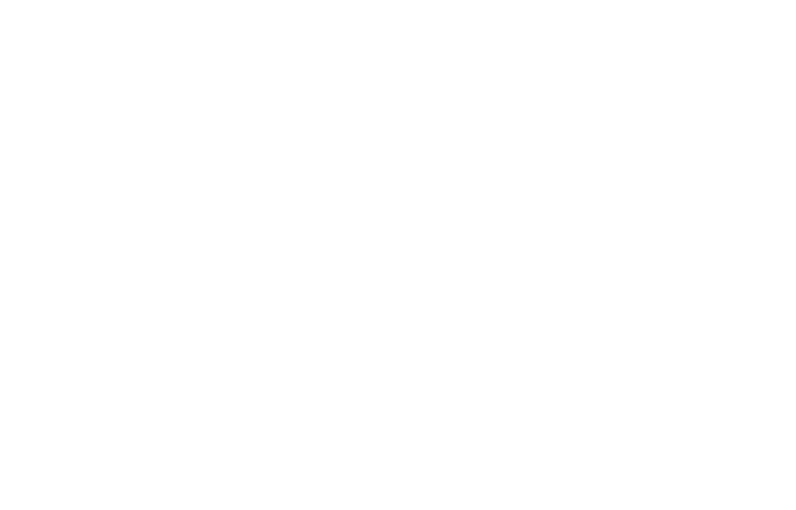

Figure 17. The course of velocity changes in the drive pipe (figure from ref. [1]).

Finally, it is worth to refer to the results in the ref. [1], which is the only comparison source with the measurements presented in this paper. It turns out that the pressure waveforms recorded by them (figure 16) are consistent with the results presented in this work. The main difference lies in the fact that Lansford and Dugan failed to register the initial peak pressure (A) and later appearing echo (B), which is probably due to measuring capabilities. Another difference concerns the proportion between the pressures in various stage of ram. This can be explained by the fact that they used a much more massive ram pump, in which the maximum pressure values were much larger, hence the difference proportion between the pressures in the various stages of operation. Accurate comparisons cannot be made due to the lack of relevant data.

In their work, ref. [1] included the graph of water velocity changes in the drive pipe (figure 17). To compare the graph presented by them with the one shown in figure 13, the water velocity waveforms changes in both valves should be imposed on each other. After performing this procedure (figure 18), it turns out that the resulting curve is qualitatively very similar.

\section{Summary}

The measurements and the analysis of the obtained results allow draw us to the following conclusions:

- It is possible to register the waveform of the pressure changes in ram pump's water flow system using electronic pressure transducers and a digital oscilloscope. The quality of the obtained results is sufficient to perform the interpretation of the phenomena occurring during the operation of the ram pump. It seems that the results presented in this paper are unique as it was not possible to find any similar studies, with the exception of work by Lansford and Dugan [1] from the $40 \mathrm{~s}$ of the last century. 


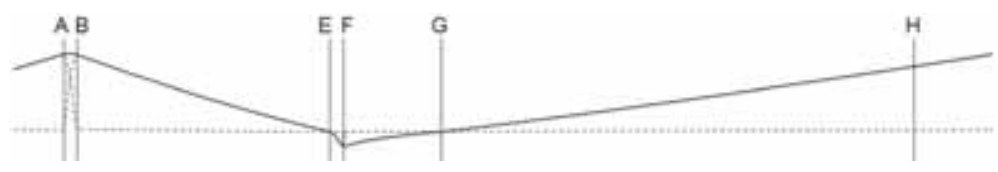

Figure 18. Estimated course of velocity changes in the drive pipe.

- Analysis of the results shows that the cycle should be divided into three main stages: acceleration, pumping and backflow. The names of the stages and their duration depend on the phenomena occurs that inside the ram. The first two stages can be further divided into phases.

- The study helped to provide a qualitative graph of the phenomena occurring in a single cycle of ram pump's work. It also appears that the graph is characteristic for all ram pumps, as the results matches four cases of examined impulse valves and is in accordance with the information contained in the work by Lansford and Dugan [1] (where number of different constructions of ram pumps have been experimentally studied also).

- The analysis of phenomena occurring in ram pump allowed developing approximate graph of velocity changes in the valves and the drive pipe. Although this graph is approximate and may have some imperfections, it is qualitatively consistent with the information from the literature, in particular with Lansford and Dugan [1] and Tayre [15] works.

- Completed interpretation of phenomena helped to explain aspects related with the start-up method of water ram (at the beginning, it was not known why the ram once starts automatically and once not).

- It was found that the time of opening/closing of the impulse valve is almost 10 times longer than the changes in the check valve. Of course, the exact value will depend on the details of construction, particularly on the difference in the masses of these heads.

- The specialist literature lacks professional studies on ram pumps, and generally accessible materials are either outdated or too imprecise (more popular than scientific). This is a result of the current marginal significance of these devices in technically leading countries and the reason why ram pumps do not constitute an area of interest in research centers.

\section{References}

[1] Lansford W L and Dugan W G 1941 An analytical and experimental study of the hydraulic ram. Urbana: University of Illinois

[2] Maruchin W and Kutienkow W 2014 Hydraulic ram—solidly forgotten old idea. http://www.pinopa.republika.pl/Tarpend_ pl.html (retrieved January 2014)
[3] Clarke J W 1900 Hydraulic rams their principle and construction. https://archive.org/details/hydraulicramsth03 clargoog (retrieved August 2014)

[4] Watt S B 1975 A manual on the hydraulic ram for pumping water. http://www.watersanitationhygiene.org/References/EH KEY_REFERENCES/WATER/Water\%20Pumping/Ram\%20 Pumps/Hydraulic\%20Ram\%20Pump\%20Manual\%20(ITDG). pdf (retrieved August 2014)

[5] Derkor 2014 How does hydraulic ram work? http://www. rampumps.net/face/20120410150106.html (retrieved March 2014)

[6] Kowalski P 2007 Analysis of the capacity of the hydraulic shock damping steel pipeline shunt plastic. Gdańsk: University of Technology.

[7] Majewski W 2015 Water management in Poland. Acta Energy 22(1): 6-12

[8] Meribah Ram Pump 2014 Sequences of operation. http:// www.meribah-ram-pump.com/index.php?id=32 (retrieved August 2014)

[9] Furze J 2012 Compendium in hydraulic ram. University of Aarhus. Faculty of Political Science. http://www.slideshare. net/Fatin62c/compendium-in-hydraulic-rampumps, (retrieved August 2014)

[10] Harkin C 2014 I made a hydraulic ram pump—and I can't even weld. Soft Technol. Mag. 22:21-24

[11] Janke K and Finger L 1994 Hydraulic ram pump. Home Power 41: 74-76

[12] Kaufman A W 1948 The popular science ram (retrieved July 2014)

[13] Marier D 1971 How it works. Alternative Source of Energy, No 1, pp. 29-31. http://www.pssurvival.com/PS/Ram_ Pumps/Compendium_In_Hydraulic_Ram-Pumps_2003.pdf

[14] Calero C 2011 Diseño y xonstrucción de una bomba de ariete hidráulico (proyecto previo a la obtención del título de ingeniero mecánico). Escuela Politécnica Nacional, Facultad De Ingeniería Mecánica, Quito (Ecuador). http://bibdigital. epn.edu.ec/bitstream/15000/4020/1/CD-3778.pdf

[15] Taye T 1998 Hydraulic ram pump. J. ESME 2(1):1-10

[16] Grygo D and Sobieski W 2015 The possibility of using water rams. Water. Environ. Rural Areas 15(2): 31-46 (in Polish)

[17] Grygo D, Sobieski W and Lipiński S 2015 Workflow water ram. J. Civil. Eng. Environ. Architech. 31(3): 95-113 (in Polish)

[18] Thorpe S, Fize D and Marlot C 1996 Speed of processing in the human visual system. Nature 381(6582): 520-522

[19] WIKA General Purpose Pressure Transmitters Type A-10. http://www.wika.us/upload/DS_PE_A_10_en_us_16479.pdf (retrieved July 2014)

[20] EZ Digital Co. 2014 Specifications. http://www.instru mentsgroup.co.za/index_files/EZdigital/Oscilloscopes/DS100 0\%20Series/DS1080C,1150C,1250C.pdf (retrieved July 2014) 
[21] Badur J et al 1999 Determining of pressure value hydraulic impact into multilayer pipes. Gdansk, Youth Forum of Mechanics, 1999, pp. 345-348 (in Polish)

[22] Nałęcz T J and Pietkiewicz P 2000a Determining of the velocity of the impact wave in closed multilayer lines. International Scientific and Technical Conference-Baltechmasz 2000, Kaliningrad, pp. 155-156 (in Polish)

[23] Nałęcz T J and Pietkiewicz P 2000b Determining of the velocity of the propagation impact wave into hydraulic lines with taking into account air as second phase. Kielce, XII National Conference Pneuma 2000, pp. 255-262 (in Polish)

[24] Nałęcz T J and Pietkiewicz P 2000c Influence of air as the second phase for the velocity propagation of shock wave into multilayer pipe. XVIII Conference of Research, Design, Production and Operating of Hydraulic Systems, Cylinder 2000, Szczyrk (in Polish)

[25] Gryboś R 1995 Fluid mechanics with hydraulics. Gliwice: Silesian University of Technology (in Polish)

[26] Nałęcz T J and Pietkiewicz P 2001 Empirical verification method for determining the velocity of propagation of the pressure shock wave. XIX Conference of Research, Design, Production and Operating of Hydraulic Systems, Cylinder '2001, Szczyrk (in Polish)

[27] Jennings G 1996 Hydraulic ram pumps. North Carolina Cooperative Extension Service. Publication Number: EBAE 161-92. Last electronic revision: March 1996 (JWM)

[28] South Carolina Irrigation Pages. Home-made hydraulic ram pump. Clemson University in South Carolina. http://www. clemson.edu/irrig/equip/ram.htm (retrieved August 2014)

[29] Calhoun J 2003 Home built hydraulic ram pumps. http:// www.homepower.com/how-ram-pump-works (retrieved August 2014)

[30] Home Power. How a ram pump works? http://www.home power.com/how-ram-pump-works (retrieved August 2014)
[31] Jong P 2014 Hydraulic rams. http://www.slideshare.net/ Fatin62c/hydraulic-ram-pump-consumers-guide-delft-univer sity-of-technology (retrieved December 2015)

[32] Mohammed S N 2007 Design and construction of a hydraulic ram pump. Leonardo Electron. J. Pract. Technol. 11: 59-70

[33] Sheikh S et al 2013 Design methodology for hydraulic ram pump. Int. J. Mech. Eng. Robot Res. 2(4): 170-175

[34] Silver M 1977 Use of hydraulic rams in Nepal. Kathmandu: UNICEF

[35] Gryboś R 1998 Fundamentals of fluid mechanics. Warsaw: PWN Publishing House (in Polish)

[36] Agriculture and Agri-Food Canada 2014 Water-powered water pumping systems for livestock watering. http://www 1 . agric.gov.ab.ca/\$department/deptdocs.nsf/ba3468a2a8681f6 9872569d60073fde1/42131e74693dcd01872572df00629626/ \$FILE/wpower.pdf (retrieved August 2014)

[37] Appropedia 2014 Hydraulic ram pumps. http://www.appro pedia.org/Hydraulic_ram_pumps (retrieved August 2014)

[38] Bergant A et al 2014 Water hammer with column separation. A review of research in the twentieth century. Eindhoven University of Technology, Department of Mathematics and Computer Science, Eindhoven (The Netherlands)

[39] KSB Group 2006 Water hammer. KSB Aktiengesellschaft, Halle KSB Know-How

[40] Larsen T 2012 Water hammer in pumped sewer mains. Aalborg University. DCE Lecture Notes 29

[41] Jeffery T D et al 1992 Hydraulic ramp pumps. Intermediate Technology Publications, pp. 126-268. ISBN 1853391727. http://www.pssurvival.com/PS/Ram_Pumps/Compendium_ In_Hydraulic_Ram-Pumps_2003.pdf 